\title{
CHANGES IN THE INCIDENCE OF ANENCEPHALUS
}

\author{
BY \\ IAN LECK* \\ Medical Unit, University College Hospital Medical School, London \\ AND \\ S. C. ROGERS \\ General Practitioner, Rugby
}

Marked changes in the incidence of anencephalus have repeatedly been observed in both Birmingham and Scotland (e.g. MacMahon, Record, and McKeown, 1951 ; Leck, 1966). These seem, however, to be the only parts of the British Isles where incidence over long periods has been studied; and even here it is not clear how much of the variation observed was due to environmental influences, and how much to alteration of the genetic constitution of the population by immigration. In this note we compare the figures previously recorded with data for Dublin, where immigration has not occurred on the same scale.

\section{MATERIAL}

In Dublin the intern and extern maternity services of three hospitals (the Rotunda Hospital, the Coombe Lying-in Hospital, and the National

* Supported by a grant from the Wates Foundation.

† Before 1960 the Rotunda Hospital began each statistical year 2 months before the calendar year, so that the years of birth shown in the Table do not apply strictly to the earlier data from this source.
Maternity Hospital) are responsible for approximately 80 per cent. of deliveries; and the annual reports of these hospitals are published in the Irish Journal of Medical Science. The annual numbers of anencephalic and total births in each intern and extern service since 1936 were extracted from these reports, and are summarized in the Table $\dagger$. To obtain most of the figures for total births it was necessary to add the numbers of second or later-born children of multiple pregnancies to the number of deliveries reported and to subtract the number of pregnancies terminating before 28 weeks, since in the majority of reports the total number of children born, including stillbirths but excluding abortions, was not given as a separate figure.

The figures given in the Table for the National Maternity Hospital are incomplete because the extern reports for 1947-53 and the intern reports for 1952-9 did not specify the frequency of anencephalus. This information was also omitted, or given only for stillbirths, in five extern reports from the other hospitals; but inspection of the numbers of births

TABLE

ANENCEPHALIC BIRTHS RECORDED IN THE REPORTS OF THE DUBLIN MATERNITY HOSPITALS, 1936-65

\begin{tabular}{|c|c|c|c|c|c|c|c|c|}
\hline \multirow{3}{*}{$\begin{array}{c}\text { Year } \\
\text { of } \\
\text { Birth }\end{array}$} & \multicolumn{6}{|c|}{ Number of Births } & \multirow{2}{*}{\multicolumn{2}{|c|}{$\begin{array}{c}\text { Incidence of Anencephalus } \\
\text { (per } 1,000 \text { total births) }\end{array}$}} \\
\hline & \multicolumn{2}{|c|}{ Rotunda Hospital } & \multicolumn{2}{|c|}{ Coombe Lying-in Hospital } & \multicolumn{2}{|c|}{ National Maternity Hospital } & & \\
\hline & Anencephalic & Total & Anencephalic & Total & Anencephalic & Total & and Coombe & National \\
\hline $\begin{array}{l}1936-7 \\
1938-9 \\
1940-1 \\
1942-3 \\
1944-5 \\
1946-7 \\
1948-9 \\
1950-1 \\
1952-3 \\
1954-5 \\
1956-7 \\
1958-9 \\
1960-1 \\
1962-3 \\
1964-5\end{array}$ & $\begin{array}{l}19 \\
40 \\
26 \\
23 \\
17 \\
34 \\
28 \\
32 \\
30 \\
41 \\
42 \\
56 \\
72 \\
54 \\
62\end{array}$ & $\begin{array}{r}8,930 \\
8,857 \\
9,631 \\
10,106 \\
10,320 \\
10,805 \\
10,804 \\
10,588 \\
10,727 \\
10,859 \\
10,571 \\
11,046 \\
10,500 \\
11,012 \\
11,584\end{array}$ & $\begin{array}{l}13 \\
11 \\
33 \\
16 \\
16 \\
16 \\
21 \\
16 \\
27 \\
36 \\
24 \\
27 \\
46 \\
26 \\
29\end{array}$ & $\begin{array}{l}5,097 \\
5,417 \\
5,586 \\
6,091 \\
5,776 \\
6,107 \\
5,868 \\
6,425 \\
6,891 \\
6,698 \\
5,622 \\
5,532 \\
6,201 \\
6,271 \\
6,434\end{array}$ & $\begin{array}{l}15 \\
27 \\
28 \\
26 \\
20 \\
= \\
= \\
= \\
= \\
- \\
71 \\
57 \\
49\end{array}$ & $\begin{array}{r}5,663 \\
6,308 \\
6,447 \\
6,581 \\
7,035 \\
= \\
= \\
= \\
= \\
9, \overline{752} \\
10,363 \\
10,346\end{array}$ & $\begin{array}{l}2 \cdot 28 \\
3 \cdot 57 \\
3 \cdot 88 \\
2.41 \\
2.05 \\
2.96 \\
2.94 \\
2.82 \\
3.24 \\
4.39 \\
4.08 \\
5.01 \\
7.07 \\
4.63 \\
5.05\end{array}$ & $\begin{array}{l}2 \cdot 65 \\
4 \cdot 28 \\
4 \cdot 34 \\
3 \cdot 95 \\
2 \cdot 84 \\
= \\
= \\
= \\
= \\
\bar{Z} \\
7 \cdot 28 \\
5 \cdot 50 \\
4 \cdot 74\end{array}$ \\
\hline Total & 576 & 156,340 & 357 & 90,016 & 293 & 62,495 & $3 \cdot 79$ & $4 \cdot 69$ \\
\hline
\end{tabular}


covered by these reports and of the statistics for adjacent years suggests that these births included less than one unreported anencephalic per year, except in 1953 when two such cases might have been expected to occur at the Coombe Hospital. This figure is incorporated in the 1952-3 statistics in the Table.

\section{Results}

Between 1936 and 1965, 246,356 live and stillbirths were recorded by the Rotunda and Coombe Hospitals; $933(3 \cdot 79 / 1,000)$ were anencephalics. The National Maternity Hospital recorded 32,034 births including 116 anencephalics $(3 \cdot 62 / 1,000)$ in $1936-45$, and 30,461 births including 177 anencephalics $(5 \cdot 81 / 1,000)$ in $1960-5$.

Changes in the incidence of anencephalus in these two populations are shown in the Table and in Fig.1. The rate for the Rotunda and Coombe hospitals rose to a peak in 1940-1, declined until 1944-5, and increased again to a second and much higher peak in 1960-1, when $0 \cdot 7$ per cent. of all births were affected.
During most of the years for which the National Maternity Hospital rate was known, it was higher than that for the other hospitals, but showed very similar fluctuations: the coefficient of correlation between the two rates was +0.95 .

\section{Discussion}

International comparisons suggest that the incidence of anencephalus in Irish hospitals is between four and seven per thousand-higher than in any other centres for which data are available (Penrose, 1957; Stevenson, Johnston, Stewart, and Golding, 1966). The incidence of cases recorded in the reports of the Dublin maternity hospitals is rather lower than these figures-partly because the Dublin reports include the statistics of the extern maternity services (relating to domiciliary births, of which relatively few are anencephalic), but probably also because not all cases are recorded; in a special study of births from March, 1953, to April, 1955, Coffey and Jessop (1957) found that the incidence of anencephalus at the Rotunda and Coombe Hospitals was

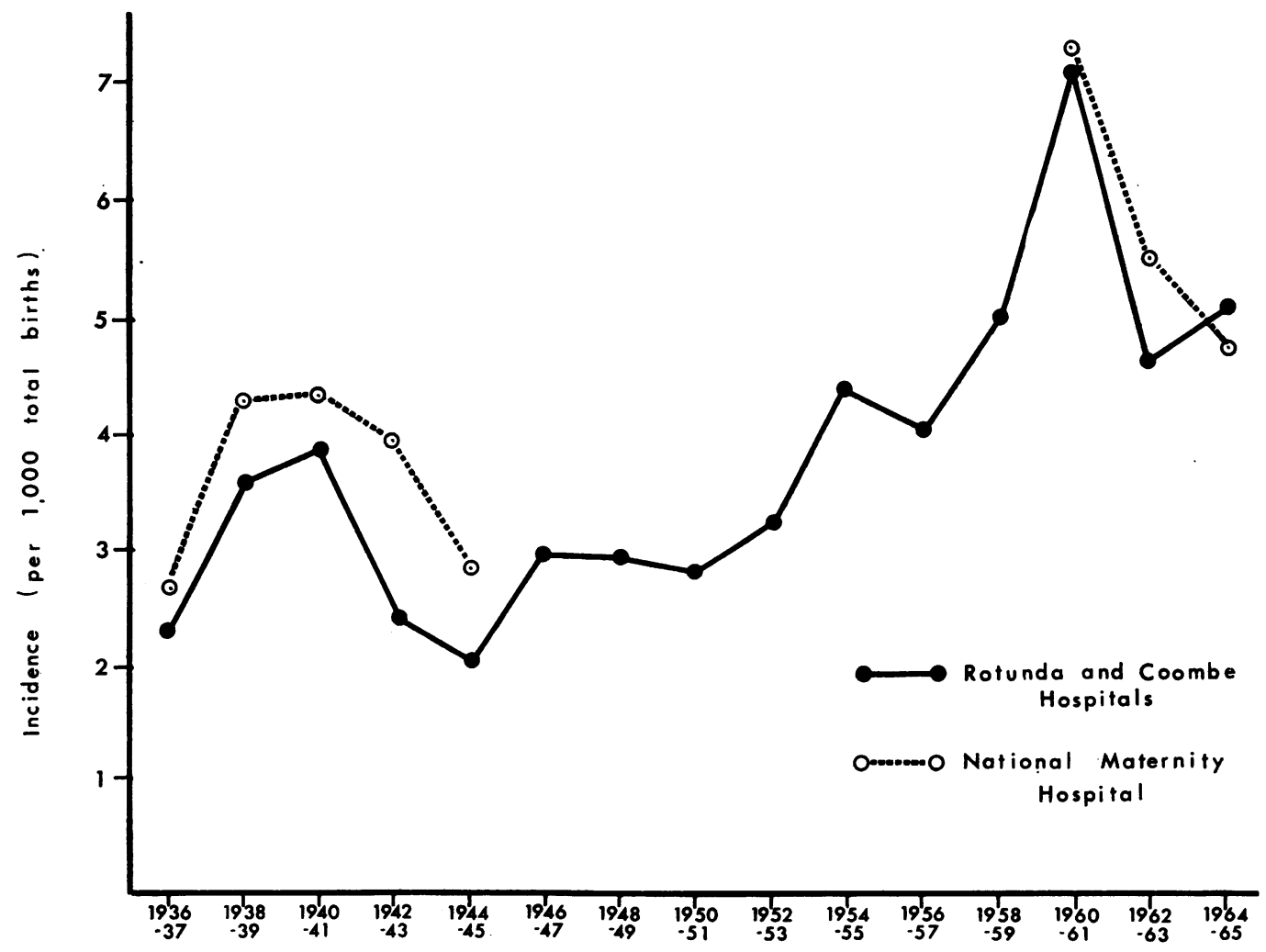

FIG. 1.-Incidence of anencephalus reported from Dublin maternity hospitals, 1936-65. 
$6 \cdot 0 / 1,000$, whereas the annual reports for 1953-5 only recorded cases in $4 \cdot 8 / 1,000$ in-patients.

This discrepancy suggests that the increase in incidence observed when hospital reports for the earlier and later years of the period 1936-65 are compared (Fig. 1) may have been due partly to improvements in ascertainment. There are, however, two reasons for believing that such changes were not the main source of variation in recorded incidence. Firstly, to account in this way for the variation observed it would be necessary to postulate that in some years only a minority of cases were reported, which seems unlikely when anencephalus is obvious and lethal. Secondly, the main features of the statistics for the Rotunda and Coombe Hospitals - the peak in $1940-1$ when incidence was about $4 / 1,000$, the rise to a rate above $7 / 1,000$ in $1960-1$, and the subsequent fall-are also exhibited by the incomplete data for the National Maternity Hospital. If these fluctuations had been due mainly to change in ascertainment, greater differences between the two sets of data might have been expected, since the hospitals concerned are separately staffed and handle their statistical data differently. We conclude that the incidence of anencephalus in Dublin is labile, and that the peaks recorded in 1940-1 and 1960-1 were genuine, although improvements in ascertainment and in the selection of cases for hospital delivery may have exaggerated the 1960-1 peak relative to the other.

The incidence of anencephalus in Scotland and Birmingham (the only other localities within the British Isles for which data have been published) also seems to have risen and fallen twice in the last 30 years (MacMahon and others, 1951; Leck, 1966), and these fluctuations are compared with the Rotunda and Coombe Hospitals' data in Fig. 2. Incidence reached its first peak in 1940-1 in Birmingham and Dublin, and in 1942-3 in Scotland. In Birmingham the second peak was about as high as the first and occurred in 1956-7, whereas in Dublin and Scotland it was higher and occurred in 1960-1. The range was much wider in Dublin than elsewhere.

The fact that in Birmingham the second increase did not continue beyond 1957 may be due to the rise

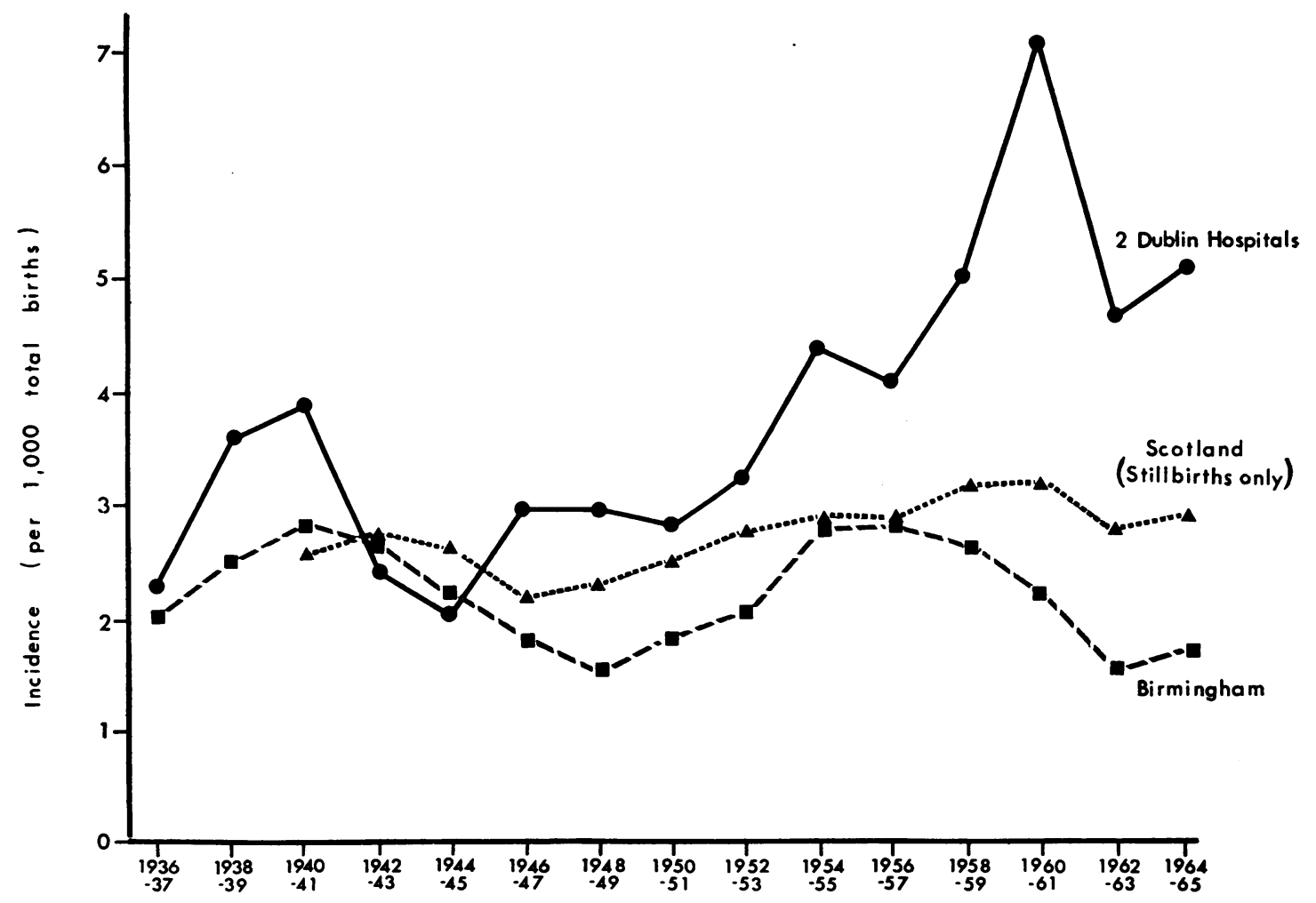

Fig. 2.-Incidence of anencephalus reported from Dublin, Birmingham, and Scotland, 1936-65. 
since then in the proportion of children born there who belong to non-European ethnic groups (in which anencephalus is relatively uncommon: Penrose, 1957; Stevenson and others, 1966). But there do not appear to have been any genetic changes of this kind which would explain the trends exhibited by the rates for Birmingham before 1957, for Scotland, and for Dublin; and as these increases and decreases occurred during approximately the same years in the three localities, it seems more likely that environmental influences common to all these areas were responsible for them. Additional evidence that the changes in different areas may have had a common aetiology is provided by the observation that both in Birmingham and in Scotland the second peak (but not the first) was due mainly to an increase in the rate among summer births, which practically eliminated the hitherto well-defined difference in incidence between summer and winter (Leck and Record. 1966).

Regarding the nature of the environmental variables believed to account for these findings, perhaps the most obvious conclusion to be drawn from the Dublin data is a negative one. As the peak in incidence observed early in the 1939-45 war in Great Britain also occurred in the Irish .Republic (a neutral country) and began there before the outbreak of war, it is unlikely to have been due to wartime hardship (a suggestion sometimes made in the light of experience in Germany, where incidence rose during the lean years after the war: Stott, 1958; Hohlbein, 1959).

\section{SUMMARY}

Analysis of maternity hospital reports suggests that twice since 1936 the incidence of anencephalus in Dublin has risen substantially and then declined. The peaks of these fluctuations occurred in 1940-1 and 1960-1.

Data already published from Scotland and Birmingham indicate that during this period incidence has also twice risen to a peak in each of these localities. These peaks were not as high as those observed in Dublin, but with one exception occurred within a year or two of them. It is concluded that environmental changes common to all three localities may have been partly responsible for the fluctuations observed.

We are grateful to Miss Juliet Harris for her help in assembling and presenting the above data.

\section{REFERENCES}

Coffey, V. P., and Jessop, W. J. E. (1957). Brit. J. prev. soc. Med., 11, 174.

Hohlbein, R. (1959). Zbl. Gynäk., 81, 719.

Leck, I. (1966). Lancet, 2, 791. 20,67 .

MacMahon, B., Record, R. G., and McKeown, T. (1951). Brit. J. soc. Med., 5, 254.

Penrose, L. S. (1957). J. ment. Defic. Res., 1, 4.

Stevenson, A. C., Johnston, H. A., Stewart, M. I. P., and Golding, D. R. (1966). "Congenital Malformations: A Report of a Study of Series of Consecutive Births in 24 Centres". (Suppl. to Bull. Wld Hlth Org., 34) W.H.O., Geneva.

Stott, D. H. (1958). J. psychosom. Res., 3, 42. 